\title{
Evidence of Heterozygous Chromosome Interchange and Chromatid Exchange in Autotetraploid Cytotype of Gibasis schiedeana (Tradescantieae-Commelinaceae)
}

\author{
Javier Martínez and Guadalupe Palomino \\ Laboratorio de Citogenética, Jardín Botánico, Instituto de Biología, \\ Apartado Postal 70-614, Ciudad Universitaria, \\ Delegación Coyoacán, México D.F. 04510, México
}

Accepted June 30, 1997

Gibasis (Kunth) D. Hunt (tribe Tradescantieae: Commelinaceae) contains 16 species most of which are tuberous perennial herbs, distributed in tropical and subtropical regions from Central America and Mexico (Jones 1978, Kenton 1982, Kenton et al. 1987, 1988). Diploid plants with $2 n=10$ and tetraploids with $2 n=16$, and basic numbers of $x=5$ and 4 , respectively, have been described in $G$. schiedeana (Jones 1974). In order to show the origin of tetraploid plants $(2 n=16)$ starting from the diploid ones $(2 n=10)$ in $G$. schiedeana, Jones (1974) carried out the hybridization of both, obtaining $F 1$ triploid hybrid plants $2 n=13$. These plants showed bivalents (IIs) trivalents (IIIs) and quadrivalents (IVs) in metaphase-I involving acrocentrics and metacentrics of the parents. From this study, Jones (1974) concluded that the tetraploid $(x=4)$ has arisen from the diploid ones $(x=5)$ by Robertsonian changes followed by chromosome doubling to produce a new basic number of $x=4$ in the genus.

Jones (1974), Jones et al. (1975), and Kenton (1984), studying several collections of $G$. schiedeana distributed in the states of Chiapas, Tabasco and San Luis Potosi, Mexico, defined six autotetraploid cytotypes of this species. These cytotypes showed different frequencies of multivalents indicating heterozygous chromosome interchange. Additionally, three of them showed 1 to $6 \mathrm{~B}$ chromosomes. The main mechanism involved in the variation and evolution of the karyotypes of this species is heterozygous interchange (Jones et al. 1975).

In the present study, the cytotype of Gibasis schiedeana from the Ecological Reserve of the Pedregal de San Angel in Mexico, D.F. (ERPSA-Mexico) is analyzed and compared to other cytotypes of $G$. schiedeana previously reported from different populations.

\section{Material and methods}

Plant material. The plants of Gibasis schiedeana (Kunth) D. Hunt studied belong to the collection of the Botanical Garden, Institute of Biology, UNAM. Voucher specimens were deposited at the National Herbarium (MEXU, Appendix 1). Live plants, from ERPSAMexico were transplanted from the field and placed in pots containing a mixture of sand and organic soil and maintained in a greenhouse.

Mitotic, meiotic chromosome and pollen fertility analyses. For the present study 15-25 plants were analyzed. Elongating secondary root tips were placed in a saturated solution of paradichlorobenzene for $6 \mathrm{hr}$ at $4^{\circ} \mathrm{C}$. They were stained following Feulgen technique (García 1990). Preparations from 75 mitotic cells were made for karyotype analysis. Chromosomes were classified according to Levan et al. (1964). Index of asymmetry (TF\%) was obtained following Gupta and Gupta (1978).

To study meiotic behavior, fresh anthers from young buds were squashed in $1.8 \%$ aceto-orcein, and 1103 pollen mother cells (PMC) in metaphase-I (M-I) and 4006 PMCs, in 
anaphase-I (A-I) were analyzed.

Pollen fertility was estimated by stained samples with cotton blue in lactophenol. Percentage of well-filled stained grains were obtained. This was carried out in 1162 pollen grains.

\section{Results}

The plants of Gibasis schiedeana analyzed were tetraploid with $2 \mathrm{n}=16$, showing a karyotype of 12 metacentrics, and four acrocentrics with a satellite in the short arm $(12 \mathrm{M}+4 \mathrm{~A}$, Table 1). Based on the mean length of the chromosomes, they were assembled in three groups of metacentrics and 1 of acrocentrics (acrocentrics=subtelocentrics, according to Levan et al.

Table 1. Cytotype of Gibasis schiedeana $(2 n=16)$ of the ERPSA-Mexico

\begin{tabular}{ccccc}
\hline \hline $\begin{array}{c}\text { Karyotype } \\
\text { formula }\end{array}$ & $\begin{array}{c}\text { Secondary } \\
\text { constrictions }\end{array}$ & $\begin{array}{c}\text { Range of chromosome } \\
\text { length }(\mu \mathrm{m})\end{array}$ & $\begin{array}{c}\text { Total haploid chromatin } \\
\text { length }(\mu \mathrm{m}) \\
\overline{\mathrm{X}} \pm \mathrm{EE}\end{array}$ & $\begin{array}{c}\text { TF }(\%) \\
\overline{\mathrm{X}} \pm \mathrm{EE}\end{array}$ \\
\hline $12 \mathrm{M}+4 \mathrm{~A}$ & $4 \mathrm{~A}$ & $6.7-13.9$ & $153.6 \pm 0.59$ & $41.34 \pm 0.22$ \\
\hline
\end{tabular}

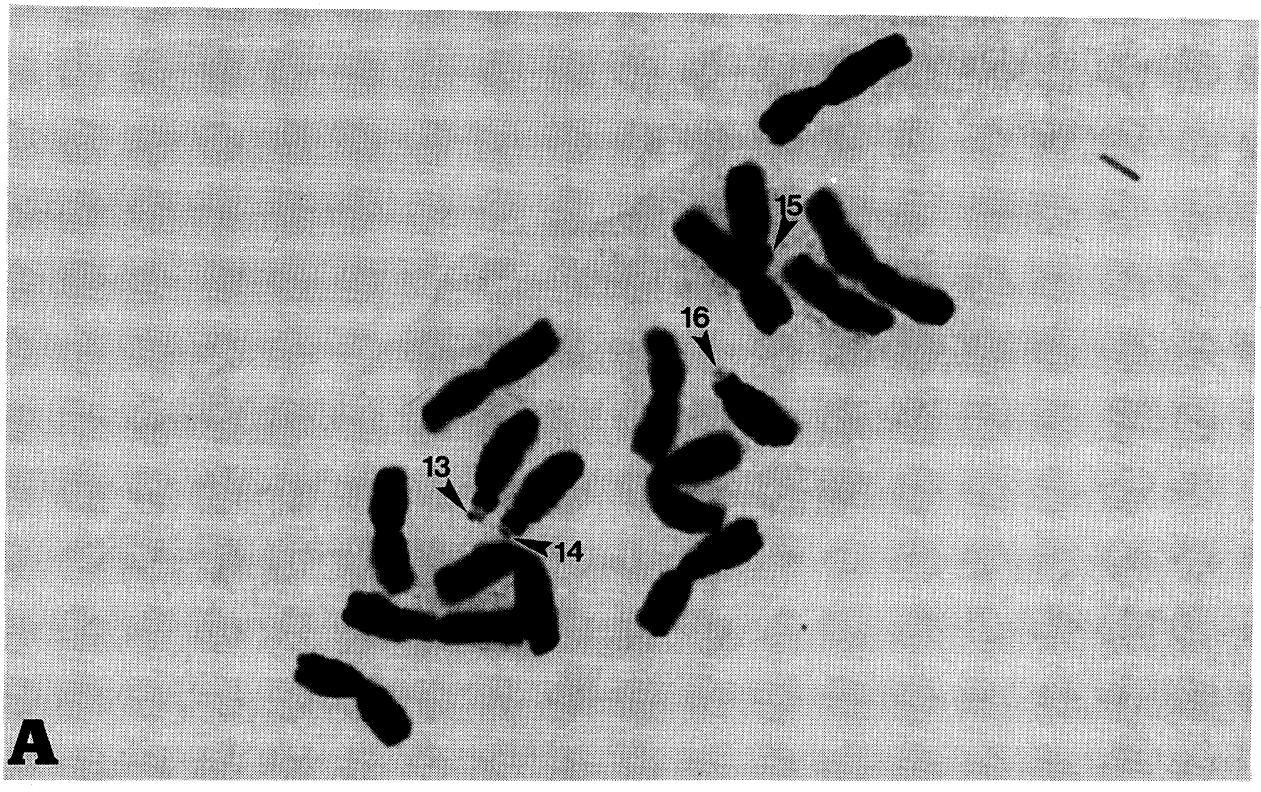

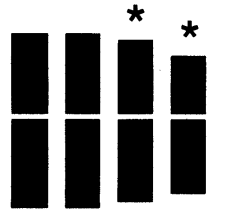

$\begin{array}{llll}1 & 2 & 3 & 4\end{array}$

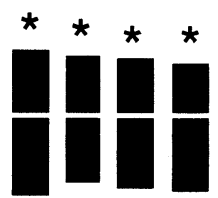

$\begin{array}{llll}5 & 6 & 7 & 8\end{array}$

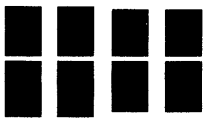

$9 \quad 101112$

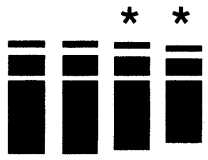

13141516

\section{$\mathbf{B}$}

Fig. 1. Cytotype of Gibasis schiedeana from ERPSA-Mexico. (A). Somatic chromosomes, 2n =16. (B). Idiogram with 12 metacentrics and four acrocentrics with a satellite. Arrows and numbers indicate satellites. Asterisks show heteromorphic chromosomes. Scale equals $10 \mu \mathrm{m}$. 

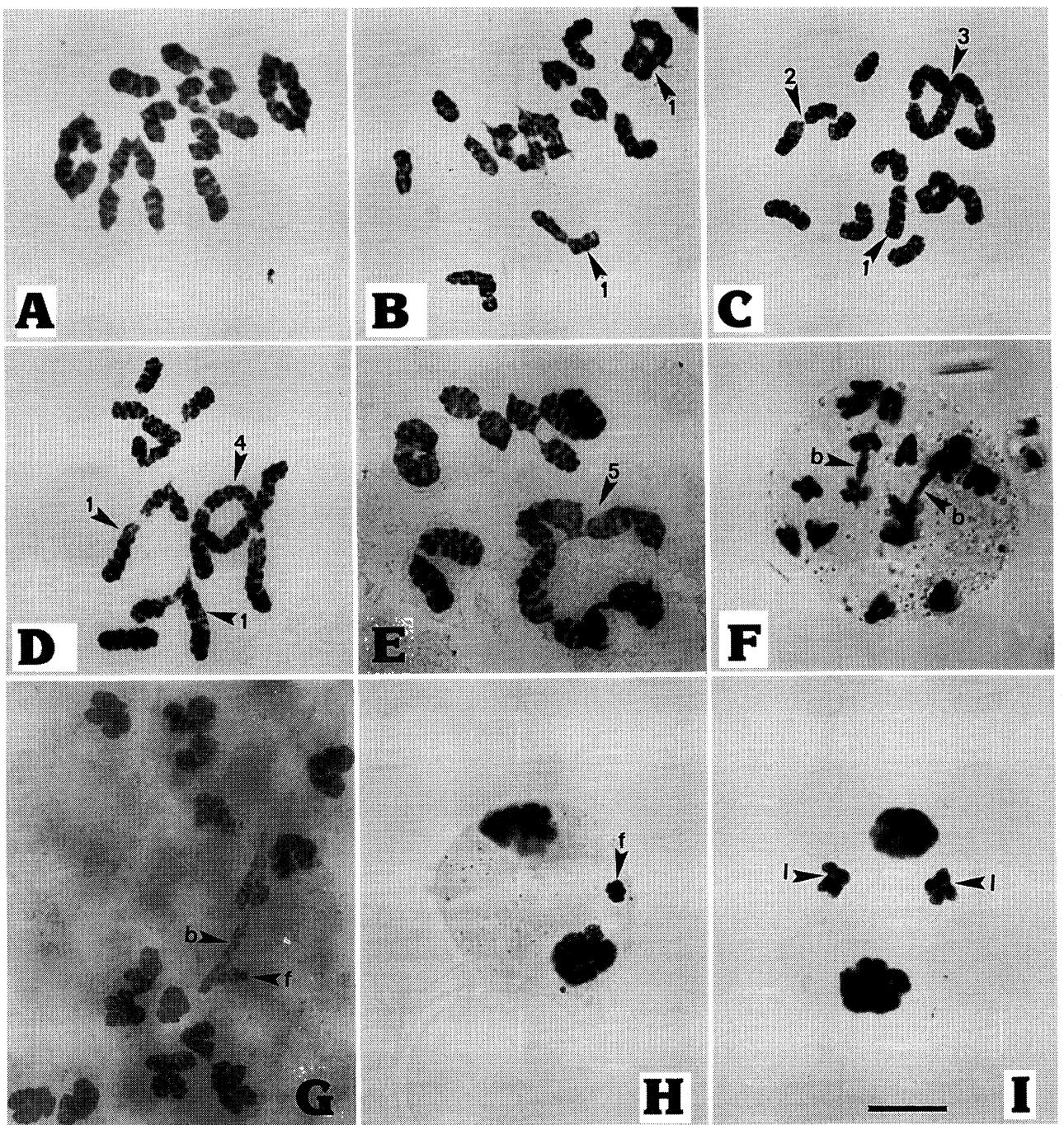

Fig. 2. PMC's showing MI and irregular AI in Gibasis schiedeana. (A). MI with $8 \mathrm{IIs}$. (B). MI with $5 \mathrm{II}+\mathrm{IV}+2$ Is. (C). MI with $2 \mathrm{IIs}+\mathrm{III}+\mathrm{IV}+5$ Is. (D). MI with $4 \mathrm{IIs}+\mathrm{V}+3$ Is. (E). MI with $3 \mathrm{II}+\mathrm{IV}+\mathrm{VI}$. (F). AI with two bridges (b). (G). AI with bridge (b) and fragment (f). (H). AI with fragment (f). (I). AI with two lagging chromosomes (I). Numbers indicate: 1. heteromorphic IIs. 2. heteromorphic IIIs. 3. heteromorphic IVs. 4. heteromorphic Vs. 5. heteromorphic VI. Scale equals $10 \mu \mathrm{m}$.

Table 2. Type and frequency of heteromorphic bivalents (IIs), and multivalents: trivalents (IIIs), quadrivalents (IVs), pentavalents (Vs) and hexavalents (VIs) of Gibasis schiedeana

\begin{tabular}{|c|c|c|c|c|c|c|}
\hline & \multicolumn{2}{|c|}{$\begin{array}{l}\text { Total of cells with bivalents } \\
\text { and multivalents }\end{array}$} & \multicolumn{2}{|c|}{$\begin{array}{l}\text { Homomorphic bivalents and } \\
\text { multivalents }\end{array}$} & \multicolumn{2}{|c|}{$\begin{array}{l}\text { Heteromorphic bivalents and } \\
\text { multivalents }\end{array}$} \\
\hline & No. & $\%$ & No. & $\%$ & No. & $\%$ \\
\hline II & 653 & 59.20 & 6589 & 76.40 & 2035 & 23.60 \\
\hline III & 10 & 0.91 & 7 & 70.00 & 3 & 30.00 \\
\hline IV & 418 & 37.90 & 591 & 73.14 & 217 & 26.86 \\
\hline V & 13 & 1.18 & 10 & 76.92 & 3 & 23.03 \\
\hline VI & 9 & 0.82 & 8 & 88.89 & 1 & 11.11 \\
\hline
\end{tabular}


Table 3. Normal and irregular anaphase-1 (A-1) of Gibasis schiedeana

\begin{tabular}{lcrc}
\hline \multicolumn{1}{c}{ PMC's in A-I } & Disjunction at A-I & PMC's \\
\cline { 3 - 4 } & & Total & $\%$ \\
\hline Number of PMC's & & 4006 & 100.00 \\
\hline Regular & $8: 8$ & 3309 & 82.60 \\
Cells with one lagging chromosome & $8: 1: 7$ & 124 & 3.10 \\
Cells with two lagging chromosomes & $8: 2: 6$ & 102 & 2.55 \\
Cells with three lagging chromosomes & $8: 3: 5$ & 68 & 1.70 \\
Cells with one bridge & & 185 & 4.62 \\
Cells with one bridge and fragment & & 164 & 4.10 \\
Cells with acentric fragment & & 54 & 1.35 \\
\hline Total of irregular PMC's & & 697 & 17.40 \\
\hline
\end{tabular}

1964). The karyotype showed 8 heteromorphic chromosomes. Within the first group they were observed in chromosomes 3 and 4; in the second group, they were observed in chromosomes 5 , 6, 7 and 8; and, in the fourth group, in chromosomes 15 and 16 (Figs. 1A, B).

The analysis of PMC's in metaphase-I showed $59.20 \%$ of the cells with bivalents only (IIs), from which $23.60 \%$ were heteromorphic (Figs. 2A, B, Table 2). $40.81 \%$ of the PMC's showed IIs and multivalent in variable combinations. The highest frequency corresponded to IIs + IVs (37.90\%), of which 26.86\% were heteromorphic (Fig. 2C, Table 2). Among those observed in lower frequencies are IIs + IIIs $(0.91 \%)$, with $30.00 \%$ of them heteromorphic, IIs $+\mathrm{V}(1.18 \%)$ with $23.03 \%$ of them heteromorphic (Fig. 2D, Table 2) and IIs + VI (0.82\%), with 11.11\% of them heteromorphic (Fig. 2E, Table 2). In the PMC's where IIs and multivalent were present, 1 to 4 univalent in a frequency of $5.35 \%$ were observed.

The analysis of PMC's in anaphase-I showed 17.40\% of irregular anaphase. $4.62 \%$ corresponded to cells with side arm bridges (SAB) without an acentric fragment and 4.10\% cells with U-type bridge associated with an acentric fragment (Figs. 2F, G, Table 3). $1.35 \%$ of irregular anaphase showed an acentric fragment (Fig. 2H, Table 3). Additionally, cells with 1, 2 and 3 lagging chromosomes in frequencies of $3.10 \%, 2.55 \%$ and $1.70 \%$ respectively were observed (Fig. 2I, Table 3).

\section{Discussion}

The plants of Gibasis schiedeana from the ERPSA-Mexico were autotetraploid with $2 \mathrm{n}=$ $16, x=4$ and a karyotype of $12 M+4 A$, which included three groups of metacentrics and one of acrocentrics with satellite, indicating their polyploid origin. The tetraploid origin of the species was also evidenced by the high frequency of quadrivalents $(37.90 \%)$ observed. These results agree with those of Jones (1974), Jones et al. (1975) and Kenton (1984) for 6 collections of $G$. schiedeana from the states of Chiapas, Tabasco, Morelos and San Luis Potosí, Mexico.

The high frequency of cells with IIs $(59.20 \%)$, as opposed to the low frequency in cells with IVs (37.90\%) in G. schiedeana from the ERPSA-Mexico, is evidence of a diploidization process. This process could be due to accumulation of heterozygous chromosome interchange that produce a gradual differentiation in its genome and alteration in gene regulation of meiosis, as Gilles and Randolph (1951) showed in Zea mays. These authors observed $88.70 \%$ of cells with IVs in the first generation of autotetraploid plants of Zea mays, diminishing to a frequency of $52 \%$ and increase of IIs, in the tenth generation. Similar diploidization mechanisms have been observed in autotetraploid plants of Nicotiana sp. (Riley and Law 1965), Avena sp. (Ladizinsky 1973), Zea perennis (Kato 1984) and Festuca sp. (Jauhar 1975, 1993). 
In the plants of Gibasis schiedeana from the ERPSA-Mexico, multivalent associations of the V (1.18\%) and VI (0.82\%) types were observed, some of them heteromorphic (Table 2), which indicated heterozygous structural interchange in their chromosomes, originating 8 heteromorphic chromosomes.

Evidence of the nature of plant heterozygosity for chromosome interchange in G. schiedeana has been well documented by Jones et al. (1975), where upon analyzing 6 populations of this species, they found cells with high frequencies of multivalents $(\mathrm{V}=3.3-6 \%, \mathrm{VI}=1-24 \%$, $\mathrm{VII}=2-3.3 \%$ and $\mathrm{VIII}=6-16 \%)$ and in lower frequencies combinations of 2 multivalents. Univalents were common in three of these cytotypes. Jones et al. (1975) observed them in frequencies of $10-30-60 \%$ of the cells, these plants were distinguished in having 1-6 B chromosomes. The G. schiedeana cytotype from the ERPSA-Mexico showed a very low frequency of univalents (5.35\%) and no B chromosomes were observed.

The divergence in the frequency of $\mathrm{V}(1.18 \%)$ and VI $(0.82 \%)$ of the cytotype of $G$. schiedeana from the ERPSA-Mexico, in relationship to the high frequencies of multivalents observed by Jones et al. (1975), indicates the variation of the cytotypes found for the several populations of Gibasis schiedeana in different locations of Mexico. The frequency of multivalents evidenced in the plants of G. schiedeana from the ERPSA-Mexico, and those observed by Jones et al. (1975) for other populations, indicates that $G$. schiedeana has a highly variable genotype, and that structural interchange in its chromosomes is the principal mechanism in its evolution.

In addition to the heterozygous chromosome interchange, the plants of $G$. schiedeana from the ERPSA-Mexico showed irregular anaphase-I (17.40\%), which included U-type (4.10\%) and SAB (4.62\%) chromatid exchange, originated from an abnormal function at the places where the chiasmata are formed, causing asymmetry in their karyotypes (Jones 1968, Brandham 1969, 1970, 1974, Brandham and Johnson 1977). Acentric fragments were also observed (1.35\%), probably resulting from sister chromatid reunion, as Kenton (1984) has observed in individual plants of $G$. linearis. Also, in G. schiedeana from the ERPSA-Mexico, the presence of 1 to 3 lagging chromosomes (7.35\%) were observed, caused by an abnormal disjunction in some of their chromosomes. The spontaneous chromatid exchange found in the present study has not been reported in previous studies of cytotypes of $G$. schiedeana. In other species of the genus, such as Gibasis consobrina, G. pulchella, G. linearis, G. venustula and G. heterophylla, these rearrangements have been evidenced in several frequencies (Jones et al. 1975, Kenton 1981, 1984). The heterozygous chromosome interchange and chromatid exchange observed in G. schiedeana from the ERPSA-Mexico, caused the formation of abnormal tetrads that originated $8.52 \%$ of non-viable pollen. In plants of Gibasis pulchella heterozygous for chromosome interchange, Jones et al. (1975), Kenton (1981) and Kenton et al. (1987), have found $50-60 \%$ reduction in pollen viability.

In summary, the presence of heterozygosity for major interchanges have played an important role in the evolution of Gibasis schiedeana. The chromatid exchanges is a mechanism also involved in the evolution of these plants.

\section{Appendix 1}

G. schiedeana. Mexico, D.F. Ecological Reserve of the Pedregal de San Angel. J. Martínez and G. Palomino 517 (MEXU).

\section{Summary}

Gibasis schiedeana from the ERPSA-Mexico, showed an autotetraploid cytotype with 
$2 n=16, x=4$ and had a karyotype $12 M+4 A$, four acrocentrics had satellites. In the cytotype from the ERPSA-Mexico, heterozygous chromosome interchange was observed, evidenced in M-I by multivalent: III (0.91\%), IV (37.90\%), V (1.18\%) and VI (0.82\%), some of them heteromorphic. In addition, the analysis in A-I showed cells with bridge and fragment (U-type chromatid exchange) and cells with bridge without fragment (sub-chromatid aberrations, SAB) in frequencies of $4.62 \%$ and $4.10 \%$ respectively. Heterozygous chromosome interchange and chromatid exchange were also evidenced in 8 heteromorphic chromosomes. Lagging chromosomes were also recorded in A-I (7.35\%). The chromatid exchange and lagging chromosomes have not been reported in other cytotypes of $G$. schiedeana.

\section{Acknowledgments}

This study was supported by CONACyT project No. 1107 P-N and Jardín Botánico of the IBUNAM. We are grateful to Dr. D. R. Hunt for the identification of the plants used in this research. To Dr. Armando García Velázquez and Dr. Fernando Chiang for their comments and suggestions on the manuscript. We also thank L. Michan and S. Michan for their technical assistance in making some slides.

\section{References}

Brandham, P. E. 1969. Inversion heterozygosity and sub-chromatid exchange in Agave stricta. Chromosoma (Berl.) 26: $270-286$.

- 1970. Chromosome behavior in the Aloineae III. Correlations between spontaneous chromatid and sub-chromatid aberrations. Chromosoma (Berl.) 31: 1-17.

- 1974. Interchange and inversion polymorphism among populations of Haworthia reinwardtii var. chalumnensis. Chromosoma (Berl.) 47: 85-108.

- and Johnson, M. A. T. 1977. Population cytology of structural and numerical chromosome variants in the Aloineae (Liliaceae). Plant Syst. Evol. 128: 105-122.

García, V. A. 1990. Manual de Técnicas y Procedimientos de Citogenética Vegetal. Tercera edición. Colegio de Postgraduados (ed.) Montecillo, Estado de México, México, 144 p.

Gilles, A. and Randolph, L. F. 1951. Reduction in quadrivalent frequency in autotetraploid maize during a period of 10 years. Amer. J. Bot. 38: 12-16.

Gupta, R. and Gupta, P. K. 1978. Karyotypic studies in the genus Crotalaria Linn. Cytologia 43: 357-369.

Jauhar, P. P. 1975 . Genetics regulation of diploid-like chromosome pairing in the hexaploid species, Festuca arundinacea Schreb and F. rubra (Gramineae). Chromosoma 52: 363-382.

- 1993. Cytogenetics of the Festuca-Lolium complex. Relevance to breeding. Monographs on theoretical and applied Genetics 18: 49-56. Springer-Verlag.

Jones, G. H. 1968. Meiotic errors in rye related to chiasma formation. Mutat. Res. 5: 385-395.

Jones, K. 1974. Chromosome evolution by Robertsonian translocation in Gibasis (Commelinaceae). Chromosoma (Berl.) 45: 353-368.

-, Papes, D. and Hunt, D. R. 1975. Contributions to the cytotaxonomy of the Commelinaceae. II. Further observations on Gibasis geniculata and its allies. Bot. J. Linn. Soc. 71: 145-166.

- 1978. Aspects of chromosome evolution in higher plants. In: Advances in Botanical Research. Woolhouse, H. W. (ed.). Academic Press, London. pp. 117-193.

- and Kenton, A. 1984. Mechanisms of chromosome change in the evolution of the tribe Tradescantieae (Commelinaceae). In: Chromosomes in evolution of eukaryotic groups. Vol. II. Sharma, A. K. and Sharma, A. (eds.). C.R.C. Press, Boca Raton, Florida, pp. 143-168.

Kato, Y. T. A. 1984. Mecanismo de diploidización en Zea perennis (Hitchcock) Reeves y Mangelsdorf. Agrociencia 58: $113-126$.

Kenton, A. 1981. Chromosome evolution in the Gibasis linearis alliance (Commelinaceae). 1. The Robertsonian differentiation of G. venustula and G. speciosa. Chromosoma (Berl:) 84: 291-304.

- 1982. Qualitative and quantitative chromosome change in the evolution of Gibasis. In: Kew Chromosome Conference II. Brandham, P. E. and Bennett, M. D. (eds.). George Allen and Unwin, London, pp. 273-282.

- 1984. Chromosome evolution in the Gibasis linearis group (Commelinaceae) III. DNA variation, chromosome 
evolution, and speciation in G. venustula and G. heterophylla. Chromosoma (Berl.) 90: 303-310.

-, Davies, A. and Jones, K. 1987. Identification of Renner complex and duplication in permanent hybrids of Gibasis pulchella (Commelinaceae). Chromosoma (Berl.) 95: 424-434.

-, Langton, D. and Coleman, J. 1988. Genomic instability in a clonal species, Tradescantia commelinoides (Commelinaceae). Genome 30: 734-744.

Ladyzinski, G. 1973. Genetic control of bivalent pairing in the Avena strigosa polyploid complex. Chromosoma 42: 105-110.

Levan, A., Fredga, K. and Sandberg, A. A. 1964. Nomenclature for centromeric position on chromosomes. Hereditas 52: 201-220.

Riley, R. and Law, C. N. 1965. Genetic variation in chromosome pairing. Adv. Genet. 13: 57-107. 